\title{
A Baby Born with Ectopia Cordis, Omphalocele, Cleft Lips and Palate: A Case Report
}

\author{
Nischal Shrestha ${ }^{1}$ \\ 'Department of Paediatrics, Nobel Medical College and Teaching Hospital, Biratnagar, Nepal.
}

\section{ABSTRACT}

Ectopia cordis is a rare congenital defect with the prevalence of 5 to 8 per million live births. Here we report a rare case of preterm female live birth with ectopia cordis associated with omphalocele, cleft lip, and palate. In this case, 14+ weeks ultrasound did not show any fetal abnormalities and parents were unaware of the condition until 35+ weeks when ultrasound detected the anomaly a few days before delivery. After delivery, they didn't give consent for further intervention which led to neonatal mortality 3 hours after birth. If the condition was diagnosed in time, an earlier intervention could have been done.

Keywords: cleft lip; cleft palate; ectopia cordis; omphalocele.

\section{INTRODUCTION}

Ectopia Cordis (EC) is a rare congenital malformation that occurs due to a defect in the fusion of the anterior chest wall resulting in complete (the naked heart is displaced outside thoracic cavity without pericardium) or partial displacement of the heart (heart can be seen pulsating through the skin) outside the thoracic cavity. ${ }^{1}$ The management of such case is surgery which is challenging because of very few cases of long term survivors. Here we present a case report of EC with omphalocele, cleft lip and palate.

\section{CASE REPORT}

A 18-year-old, unbooked primigravida, $O$ positive blood group, Mongolian race presented with complaints of decreased fetal movement for three days. The mother was not suffering from any illness during pregnancy. There was no history of infection, intake of any teratogenic drugs, or exposure to any radiation in the antenatal period. There was no family history of congenital anomalies. There was no history of consanguinity. Her $14^{+}$weeks of gestation (WOG) ultrasonography (USG) showed no gross fetal abnormality. But her USG at $35^{+2}$ WOG showed fetal abnormalities. Both the woman and her family were aware of the USG report.

The USG findings can be summarized as: in the $14^{+}$ WOG, no gross fetal abnormality was evident. The presentation was breech with anterior placentation and adequate liquor volume: in the $35^{\text {th }}$ week, the heart of the fetus appeared outside the thoracic cavity (abdomino-thoracic type of Ectopia Cordis) (Figure 1), solid structure mainly liver appeared away from the anterior abdominal wall (Omphalocele), upper lip region showed lucency (cleft palate), amniotic fluid index (AFI) was $50.8 \mathrm{~cm}$ (polyhydramnios) with breech presentation (Figure 2).

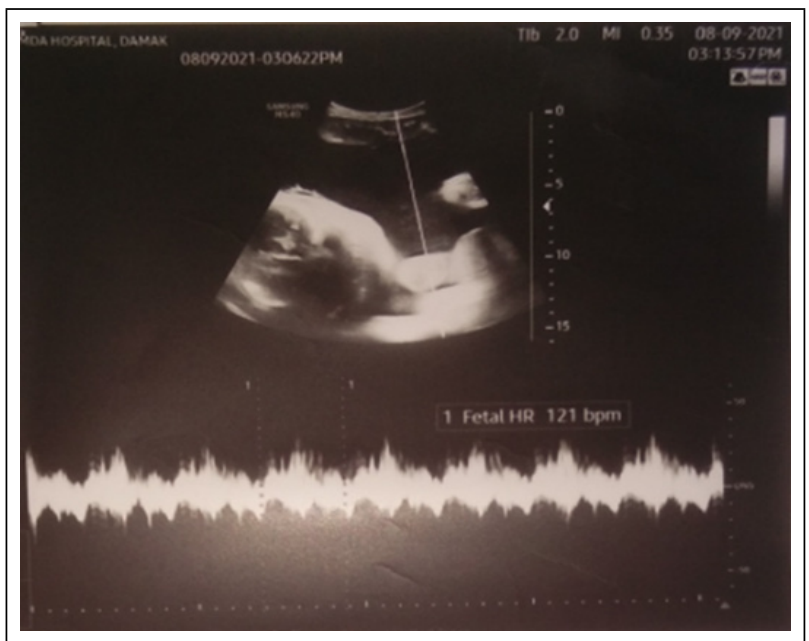

Figure 1. Ectopia cordis.

Correspondence: $\mathrm{Dr}$ Nischal Shrestha, Department of Paediatrics, Nobel Medical College and Teaching Hospital, Biratnagar, Nepal. Email: shresthasnisal@gmail.com, Phone: +9779849943448 . 


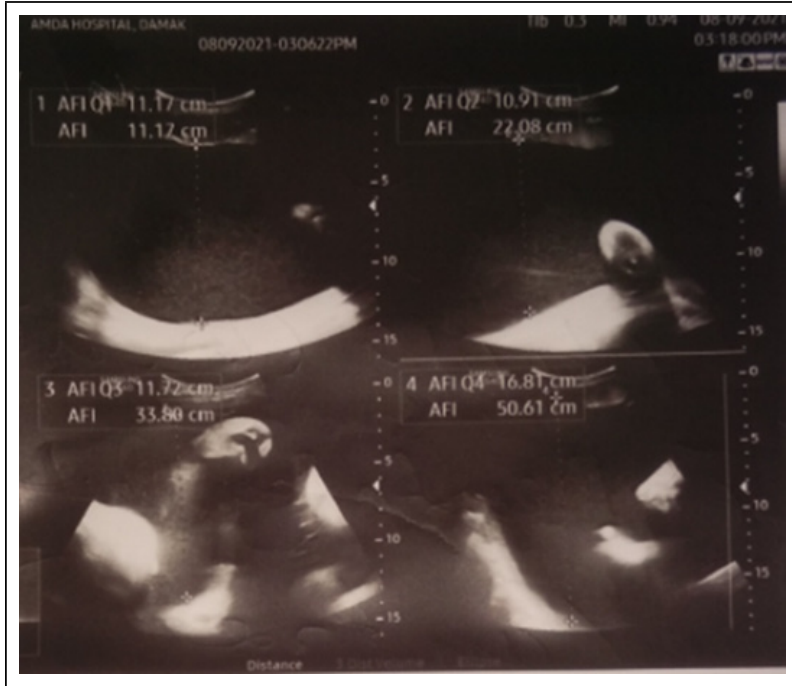

Figure 2. Polyhydramnios.

A live preterm female baby of $2 \mathrm{kgs}$ was born at the $35^{+5}$ WOG by spontaneous vaginal delivery at a tertiary care centre of Nepal. The newborn had an APGAR score of seven and eight in the $1^{\text {st }}$ and $5^{\text {th }}$ minutes, respectively. An anterior thoracoabdominal defect with extrathoracic heart, a cleft sternum, omphalocele, bilateral cleft lip, and palate was recognized at birth. On gross examination, the heart was totally outside of the thoracic cavity without pericardium protection. There was an abdominal wall defect with supraumbilical omphalocele where the umbilical cord was attached at the lower part of the defect (Figure 3).

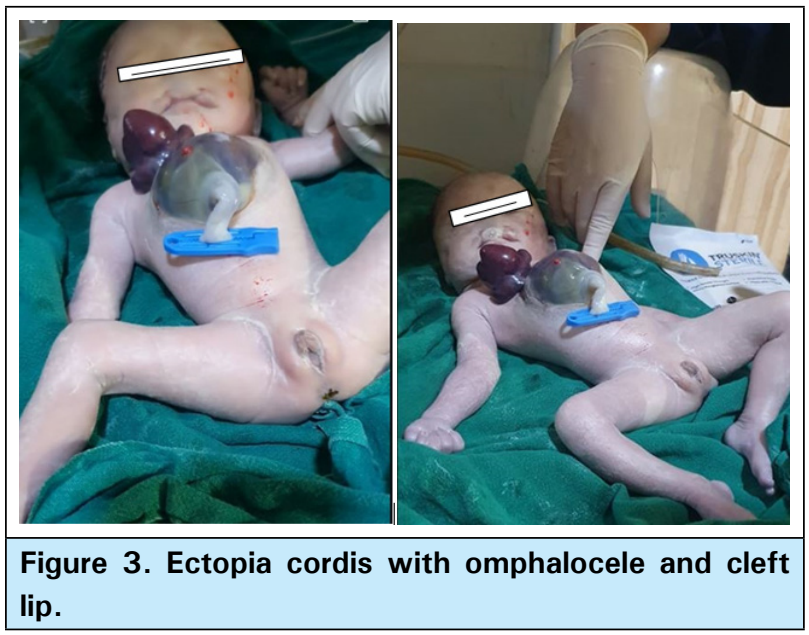

Other abnormal features included telecanthus (broad nasal bridge). The mother and her family refused for admission of the baby. As a result of progressive respiratory dysfunction, neonatal death occurred in the first three hours of life. The family did not allow to perform an autopsy examination. The neonate died in her first three hours before any surgical intervention was done.

\section{DISCUSSION}

Haller, et al. in 1706 described the term ectopia cordis for the first time. ${ }^{2}$ But, the cause is yet unknown; however, it has been reported that EC may be associated with chromosomal disorders including trisomy 18, Turner syndrome, $46 X X$, and $17 q+$, viral infections and exposure to teratogens. ${ }^{2,3}$ On physical examination, in this case, telecanthus was noted which might be associated with chromosomal disorders like Turner's syndrome, Down's syndrome, ${ }^{4}$ but the chromosomal analysis could not be done as consent was not given.

EC occurs mostly sporadically; also, in this case, no family history was known. Only a few cases of familial EC have been reported. ${ }^{5}$ The reported prevalence is five to eight per million live births. It constitutes $0.1 \%$ of all congenital heart diseases. It has shown its association with cardiac anomalies such as ventricular septal defects (VSDs), atrial septal defects (ASDs), pulmonary stenosis (PS), right ventricular (RV) diverticulum, double outlet right ventricle (DORV), and tetralogy of Fallot. ${ }^{6}$ Very few cases of EC with double outlet right ventricle have been reported till now.,8 In this case, we couldn't find out intracardiac anomaly as we could not perform echocardiography. Non-cardiac disorders such as omphalocele, gastroschisis, scoliosis, cleft palate/lip, and central nervous system disorders have also been seen with EC. ${ }^{9}$ Similar to reports by Taksande and Morales, this case had omphalocele and cleft lip/palate associated with EC. ${ }^{9,10}$

Embryogenesis reveals that the development of the ventral body wall begins with differentiation and proliferation of mesoderm followed by its lateral migration by the eighth day of the embryonic life. The heart initially develops in cephalic location but reaches its ultimate position by lateral folding and ventral flexing of the embryo at about the $16^{\text {th }}-17^{\text {th }}$ day. By the $9^{\text {th }}$-week midline fusion occurs and the formation of the thoracic and abdominal cavities completes. If there is a complete failure of midline fusion at this stage, then complete ventral evisceration occurs. Isolated EC occurs if there is incomplete midline fusion. ${ }^{6,11} \mathrm{EC}$ can be classified on the basis of the location of the heart into 5 types: cervical (5\%), cervicothoracic and thoracic $(65 \%)$, thoracoabdominal $(20 \%)$, and abdominal $(10 \%) .{ }^{12}$ If along with thoracoabdominal EC, there occurs lower sternal defect, anterior diaphragmatic hernia, midline supraumbilical abdominal wall defect, and intracardiac defects, then the condition is termed as Pentalogy of Cantrell. ${ }^{13}$ In this case, we could see thoracoabdominal EC which usually accompanies Cantrell's syndrome but we could not find out if there was an intracardiac defect as we were unable to do an echocardiogram. A similar case with the Pentalogy of Cantrell was reported by Kumar B, et al. ${ }^{14}$ 
Prenatally we can diagnose EC using 2D ultrasound as early as in 10-12 weeks of pregnancy. ${ }^{15}$ For the firsttrimester diagnosis, 2D is sufficient, while 3D has greater usefulness in the $2^{\text {nd }}$ and $3^{\text {rd }}$ trimesters. ${ }^{16,17}$ Omphalocele can be detected early at the $12^{\text {th }}$ week of menstrual age. But in this case, the $14^{+}$weeks scan did not show any gross abnormality. Abnormality was identified only in $35^{+}$weeks USG. MRI in conjunction with prenatal echocardiography allows optimal assessment of the fetus with ectopia cordis and omphalocele. ${ }^{18}$ We can diagnose cleft lip and palate using $2 D$ and $3 D$ USG in the $2^{\text {nd }}$ and $3^{\text {rd }}$ trimesters. Data of accurate diagnosis in 1 st trimester is lacking. ${ }^{19}$

The complete EC (as our case) where the heart is completely outside the thoracic cavity, is a neonatal emergency. The initial management of EC is concerned with immediate covering the heart and exposed abdominal contents (omphalocele). For this, silastic prosthesis is recommended. Before closing the abdominal wall, we should evaluate and correct intracardiac defects. ${ }^{20}$ Surgical repair of omphalocele is done within the first 72 hours of life. Commonly surgical repair of cleft lip and palate is done at $12^{\text {th }}$ month of life. The management of such cases is a multistep, complicated, and expensive process, with a poor prognosis. So, even if the case was detected earlier and intervention would have been taken in time, the probability of a better outcome would be low. In this case, the family came to know about the fetal condition through ultrasound just a few days before delivery at our hospital and after the delivery, they refused the admission of the baby to NICU. Therefore, no intervention could be tried and the baby died within 3 hours due to respiratory failure.

As the patient did not follow up from the beginning, detailed information regarding the case could not be reported in this case report. Also, we could not diagnose the case early and intervention could not be done. Therefore, WHO guidelines for a pregnant woman regarding antenatal care visit and ultrasonography is recommended. If any serious abnormality is detected, termination can be a choice so that it will not be a burden for the mother and also the baby after birth will not have to suffer.

\section{Conflict of Interest: None.}

Consent: JNMA Case Report Consent Form was signed by the patient and the original article is attached with the patient's chart.

\section{REFERENCES}

1. Engum SA. Embryology, sternal clefts, ectopia cordis, and Cantrell's pentalogy. Semin Pediatr Surg. 2008 Aug;17(3):154-60. [PubMed | Full Text | DOI]

2. Shad J, Budhwani K, Biswas R. Thoracic ectopia cordis. BMJ Case Rep. 2012 Sep 30;2012:bcr1120115241. [PubMed | Full $\underline{\text { Text }} \mid \underline{\mathrm{DOI}}]$

3. Khoury MJ, Cordero JF, Rasmussen S. Ectopia cordis, midline defects and chromosome abnormalities: an epidemiologic perspective. Am J Med Genet. 1988 Jul;30(3):811-7. [uuMed | Full Text | DOI]

4. Bhansali A, Aggarwal A, Parthan G, Gogate Y, editors. Clinical Rounds in Endocrinology. vol. II, Turner Syndrome. New Delhi: Springer,2016.261-90p. [Full Text | DOI]

5. Martin RA, Cunniff C, Erickson L, Jones KL. Pentalogy of Cantrell and ectopia cordis, a familial developmental field complex. Am J Med Genet. 1992 Apr 1;42(6):839-41. [PubMed | Full Text | DOI]

6. Cantrell JR, Haller JA, Ravitch MM. A syndrome of congenital defects involving the abdominal wall, sternum, diaphragm, pericardium, and heart. Surg Gynecol Obstet. 1958 Nov;107(5):602-14. [PubMed | Full Text]

7. Trever RW,SchmidtEC, BaybuttJ. Ectopia cordis with double outlet right ventricle. Am J Cardiol. 1966 Nov;18(5):785-7. [PubMed | Full Text $\mid \underline{\text { DOI] }}$

8. Malik R, Zilberman MV, Tang L, Miller S, Pandian NG. Ectopia cordis with a double outlet right ventricle, large ventricular septal defect, malposed great arteries and left ventricular hypoplasia. Echocardiography. 2015 Mar;32(3):589-91. [ [PubMed | Full Text | DOI]

9. Morales JM, Patel SG, Duff JA, Villareal RL, Simpson JW. Ectopia cordis and other midline defects. Ann Thorac Surg. 2000 Jul;70(1):111-4. [uued | Full Text | DOI]

10. Taksande AM, Vilhekar KY. A case report of ectopia cordis and omphalocele. Indian J Hum Genet. 2013 Oct;19(4):491-3. [PubMed | Full Text | DOI]

11. Kanagasuntheram R, Verzin JA. Ectopia cordis in man. Thorax. 1962 Jun;17(2):159-67. [ubMed | Full Text | DOI]

12. Anderson RH, Baker EJ, Penny D, Redington AN, Rigby ML, Wernovsky G. Paediatric Cardiology. 3rd ed. London: Churchill Livingstone Elsevier; 2009, 1344p. [Full Text]

13. Chandran S, Ari D. Pentalogy of cantrell: an extremely rare congenital anomaly. J Clin Neonatol. 2013 Apr;2(2):95-7. [PubMed | Full Text | DOI]

14. Kumar B, Sharma C, Sinha DD, Sumanlata. Ectopia cordis associated with Cantrell's pentalogy. Ann Thorac Med. 2008 Oct;3(4):152-3. [PubMed | Full Text | DOI]

15. Ergenoglu MA, Yeniel AO, Peker N, Kazandı M, Akercan F, Sagol S. Prenatal diagnosis of Cantrell pentalogy in first trimester screening: case report and review of literature. J Turk Ger Gynecol Assoc. 2012 Jun 1;13(2):145-8. [PubMed | Full Text | DOI]

16. Peixoto-Filho FM, do Cima LC, Nakamura-Pereira M. Prenatal diagnosis of Pentalogy of Cantrell in the first 
trimester: is 3-dimensional sonography needed? J Clin Ultrasound. 2009 Feb;37(2):112-4. [PubMed | Full Text | $\underline{\mathrm{DOI}}]$

17. Araujo Junior E, Carrilho MC, Toneto BR, Guilhen JCS. Pentalogy of Cantrell: Prenatal Diagnosis, Delivery, and Immediate Postnatal Surgical Repair. J Neonatal Surg. 2017 Apr 15;6(2):32. [PubMed | Full Text | DOI]

18. McMahon CJ, Taylor MD, Cassady CI, Olutoye OO, Bezold LI. Diagnosis of pentalogy of cantrell in the fetus using magnetic resonance imaging and ultrasound. Pediatr Cardiol. 2007 May-Jun;28(3):172-5. [ $\underline{\text { PubMed } \mid ~}$ Full Text | $\underline{\mathrm{DOI}}]$
19. Martinez-Ten P, Adiego B, Illescas T, Bermejo C, Wong AE, Sepulveda W. First-trimester diagnosis of cleft lip and palate using three-dimensional ultrasound. Ultrasound Obstet Gynecol. 2012 Jul;40(1):40-6. [PubMed | Full Text | DOI]

20. Harrison MR, Filly RA, Stanger P, de Lorimier AA. Prenatal diagnosis and management of omphalocele and ectopia cordis. J Pediatr Surg. 1982 Feb;17(1):64-6. [PubMed | Full $\underline{\text { Text }}$ | DOI]

\section{The Author(s) 2022.}

This work is licensed under a Creative Commons Attribution 4.0 International License. The images or other third party material in this article are included in the article's Creative Commons license, unless indicated otherwise in the credit line; if the material is not included under the Creative Commons license, users will need to obtain permission from the license holder to reproduce the material. To view a copy of this license, visit http://creativecommons.org/licenses/by/4.0/ 